\title{
Os direitos humanos de pacientes em risco de suicídio no Brasil
}

The human rights of patients in suicide risk in Brazil

Los derechos humanos de los pacientes con riesgo suicida en Brasil

\author{
Aline Albuquerque ${ }^{1}$ \\ Laura Boeira ${ }^{2}$ \\ Luana Lima ${ }^{3}$ \\ Thatiana Ayres ${ }^{4}$
}

\section{Resumo}

Objetivo: analisar a temática do suicídio na perspectiva teórico-normativa dos direitos humanos dos pacientes. Metodologia: foi realizada pesquisa teórica e documental sobre os aspectos éticos e de direitos humanos dos pacientes em risco/tentativa de suicídio. Resultados: foram observadas violações aos direitos humanos dos pacientes em risco de saúde, nos serviços de saúde. Conclusão: é necessária a adoção de medidas para promover a alteração da situação de violação de tais direitos.

Palavras-chave: Direitos humanos. Suicídio. Pacientes. Bioética.

\begin{abstract}
Objective: to analyze the subject of suicide in the theoretical-normative perspective of the human rights of patients. Methodology: theoretical and documentary research on the ethical and human rights aspects of patients at risk/suicide attempt. Results: violations of the human rights of patients at health risk were observed in the health services. Conclusion: it is necessary to adopt measures to promote the alteration of the situation of violation of these rights.
\end{abstract}

Keywords: Human rights. Suicide. Patients. Bioethics.

\section{Resumen}

Objetivo: analizar la temática del suicidio en la perspectiva teórico-normativa de los derechos humanos de los pacientes. Metodología: se realizó una investigación teórica y documental sobre los aspectos éticos y de derechos humanos de los pacientes en riesgo / intento de suicidio. Resultados: se observaron violaciones a los derechos humanos de los pacientes en riesgo de salud, en los servicios de salud. Conclusión: es necesaria la adopción de medidas para promover la alteración de la situación de violación de tales derechos.

Palabras clave: Derechos humanos. El suicidio. Los pacientes. Bioética.

\footnotetext{
${ }^{1}$ Professora de Bioética e Direitos Humanos do Programa de Pós-Graduação em Bioética da UnB. E-mail: alineaoliveira@hotmail.com

2 Psicóloga pela UFRGS, mestre em Bioética pela UnB, especialista em oncohematologia (RIS-GHC) e gestão de redes de atenção em saúde pela Fiocruz. E-mail: boeira.lb@gmail.com

${ }^{3}$ Doutoranda e mestra em Bioética pela UnB, psicóloga e bacharel interdisciplinar em Humanidades (UFBA). E-mail: luanalima.sc@outlook.com

${ }^{4}$ Terapeuta ocupacional pela PUC-Goiás, mestre em Bioética pela UnB. E-mail: athatiana7@gmail.com
} 


\section{Introdução}

O suicídio, como processo sócio-histórico, é um fenômeno de grande complexidade para o campo da saúde pública e dos direitos humanos. Apesar da tendência internacional que delineia o dever do Estado de proteger a vida do paciente em risco de suicídio, o último relatório temático da Organização Mundial de Saúde evidencia a gravidade do tema mediante o registro de mais de 800 mil óbitos anuais por essa causa no mundo (1). No cenário nacional, apesar da adoção das Diretrizes Nacionais para Prevenção do Suicídio em 2006 (2), observa-se uma curva ascendente do fenômeno no Brasil, quarto país latinoamericano com maior crescimento do número de suicídios entre 2000 e 2012 (1). A despeito de, no Brasil, os dados sobre tentativa de suicídio serem passíveis de notificação imediata e compulsória, desde 2011, reconhece-se o problema da sua subnotificação.

As situações de vulnerabilidade que implicam o risco de suicídio referem-se a traumas; abuso; dor crônica; transtornos mentais; história familiar de suicídio; tentativa anterior; estigma frente ao comportamento de busca de ajuda; e ainda, fatores de risco associados aos sistemas de saúde, tais como barreiras no acesso que podem ser retroalimentadas pelo estigma (1), evidenciando problemas das instituições de saúde, tanto técnicos quanto éticos. A importância da tentativa anterior de suicídio como fator de risco primordial é corroborada por estudos (1) (3) (4), que indicam a importância da atuação dos profissionais que cuidam dos pacientes após a tentativa.

Além do número incipiente de pesquisas sobre suicídio, no Brasil e na esfera internacional, há absoluta escassez de estudos acerca dos pacientes em risco de suicídio sob a perspectiva dos direitos humanos. Este artigo se propõe, portanto, a apresentar um ponto de vista inovador acerca desse tema de inegável impacto social e individual. A inserção do referencial teórico-normativo dos direitos humanos na esfera da saúde pública e dos cuidados em saúde é essencial para o fomento da atuação dos profissionais de saúde em prol do respeito, proteção e realização dos direitos humanos, na medida em que são atores sociais decisivos no enfrentamento das situações violadoras de direitos humanos.

O paciente em risco de suicídio comumente não tem atendimento em serviços qualificados, sendo sujeito a julgamentos discriminatórios e submetido a condições desumanas e degradantes (5) (6) (7), sendo seus direitos constantemente violados. 
Considerando tal quadro, este artigo busca incorporar o referencial teórico-normativo dos direitos humanos dos pacientes ao contexto do cuidado do paciente em risco de suicídio. Como objetivo adicional, pretende-se analisar a violação de tais direitos, a partir do exame do relatório sobre Direitos Humanos dos Pacientes em Risco de Suicídio no Brasil, elaborado pelo Observatório de Bioética e Direitos Humanos, do Programa de PósGraduação em Bioética da Universidade de Brasília (UnB) (7).

Quanto à metodologia, trata-se de pesquisa teórica e documental que envolveu o levantamento e a análise de artigos sobre os aspectos éticos e de direitos humanos dos pacientes em risco/tentativa de suicídio, bem como o exame do supracitado Relatório sobre Direitos Humanos dos Pacientes em Risco de Suicídio no Brasil, particularmente a parte referente às entrevistas com profissionais de saúde, familiares e pacientes relacionados ao tema do suicídio.

\section{Direitos humanos dos pacientes}

Os direitos humanos dos pacientes são um ramo do direito internacional dos direitos humanos, que abarcam o conjunto de convenções, pactos e declarações internacionais em matéria de direitos humanos, bem como a jurisprudência internacional construída pelos órgãos de monitoramento dos direitos humanos da Organização das Nações Unidas (ONU), do Sistema Europeu de Proteção dos Direitos Humanos, do Sistema Interamericano de Direitos Humanos e do Sistema Africano de Proteção dos Direitos Humanos. Dessa forma, nota-se que os Direitos Humanos dos Pacientes, enquanto ramo do direito internacional dos direitos humanos, extraem seu arcabouço teórico da jurisprudência internacional e documentos adotados no âmbito de organismos internacionais (8).

A abordagem teórica do tema se fundamenta nos estudos de Albuquerque (8) e de Cohen e Ezer (9) sobre os direitos humanos nos cuidados do paciente. Contudo, a abordagem de Cohen e Ezer tem uma proposta mais ampla, ao articular um referencial que abarca todos os tipos de violação que ocorram no âmbito dos cuidados em saúde (9).

Cabe destacar que os direitos humanos dos pacientes derivam da dignidade humana inerente a todo ser humano e da lógica do cuidado (10), apartando-se da lógica do mercado e das bases consumeristas que alicerçam os direitos do paciente, enquanto consumidor. Com efeito, sob essa perspectiva, os cuidados com o paciente, como 
elementos interligados aos direitos humanos, merecem especial atenção. Verificam-se, cotidianamente, no contexto dos cuidados ao paciente, variadas violações de direitos humanos. Tais abusos, consubstanciados na ofensa ao direito à privacidade, à confidencialidade de informações pessoais, na prática de atos discriminatórios, no tratamento desumano ou degradante, no desrespeito à autodeterminação e à escolha esclarecida, dentre outros, não apenas violam os direitos, como também impactam negativamente nos resultados do tratamento (9). Nessa linha, cumpre assinalar que os direitos humanos dos pacientes compreendem direitos previstos em normas internacionais que se conectam diretamente com o contexto dos cuidados em saúde dos pacientes: direito à vida; direito a não ser submetido à tortura, ou a tratamentos ou penas cruéis, desumanos ou degradantes; direito à liberdade e segurança pessoal; direito ao respeito à vida privada; direito à informação; direito de não ser discriminado; e direito à saúde.

\section{Direitos humanos dos pacientes em risco de suicídio}

A análise das condições do cuidado do paciente em risco/tentativa de suicídio implica a identificação de direitos humanos específicos que Ihes são aplicáveis. Com vistas a essa identificação, o presente estudo se ancorou no elenco de direitos humanos dos pacientes proposto por Albuquerque (8), assim como em pesquisa na literatura especializada sobre suicídio no Brasil (7).

Assim, quanto aos direitos humanos dos pacientes que incidem nos cuidados daqueles que se encontram em risco/tentativa de suicídio, sob o prisma do Sistema de Direitos Humanos da ONU, destaca-se o artigo $4^{\circ}$ do Pacto Internacional sobre os Direitos Civis e Políticos que prevê o direito à vida. Já o artigo $7^{\circ}$ estabelece o direito de não ser submetido à tortura ou a tratamento desumano ou degradante; o artigo $9^{\circ}$, o direito à privacidade; o artigo 13, o direito à liberdade; o artigo 15, o direito à informação; e o artigo 26, o direito de não ser discriminado. No âmbito do Pacto Internacional sobre os Direitos Econômicos, Sociais e Culturais, registra-se o artigo 12, que prevê o direito à saúde. Sendo assim, a partir desse rol de direitos, foram identificadas, na literatura especializada, situações violadoras dos direitos humanos dos pacientes em risco/tentativa de suicídio no Brasil.

Vidal e Gontijo realizaram uma pesquisa com intuito de investigar o acolhimento a pessoas em tentativa de suicídio nos serviços de urgência através da percepção de quem 
tenta (6). Entre os resultados, foram citadas situações de discriminação e atitudes negativas de toda a equipe, dos funcionários da recepção até enfermagem e médicos. As expressões de sofrimento eram nomeadas como manifestações histéricas, tratadas com descrédito, descaso, de forma hostil e desumana, especialmente nas ocorrências em que não havia risco de morte.

Esse quadro é ratificado pelo estudo de Tavares que, ao ouvir o depoimento de um profissional, registrou procedimentos desnecessários como uma prescrição e administração de lavagem gástrica - justificada pela entrevistada como uma indicação supostamente terapêutica, uma forma de "mostrar para o paciente o que é bom!" (12). O sarcasmo em questão projeta o conteúdo agressivo da ação, assim como comunica ao paciente que ali não é o lugar para buscar apoio para o seu sofrimento. Outro profissional de saúde entrevistado no trabalho de Marquetti (5) reproduziu a força desse discurso: "É para ele não repetir aquilo, aprender a não atrapalhar quem está trabalhando e que existem outros pacientes que desejam viver e precisam de cuidados." $O$ ato de dizer não à existência parece delinear um confronto perante a ordem e ética médica, que realiza todos os esforços em direção à preservação da vida (13).

Em decorrência da compreensão da tentativa de suicídio como um ato impregnado de intencionalidade, resultante de uma escolha, esse paciente é categorizado como aquele que não precisa de cuidados (6). A negação ou subversão do cuidado reflete o preconceito e desinformação das tentativas de suicídio como um pedido de ajuda (6), bem como viola os direitos de não ser discriminado e de não ser submetido a tratamentos degradantes. $\mathrm{Na}$ contramão da negligência, torna-se imperativo às condutas dos profissionais uma escuta com cordialidade, um tratamento com respeito e empatia com as emoções do paciente (14).

Na maioria das vezes, os pacientes são liberados da emergência sem passar por avaliação psiquiátrica e não têm encaminhamento para serviços especializados (6) oportunidades perdidas para instituir e/ou dar continuidade ao tratamento, além de caracterizar descumprimento dos direitos à saúde e informação. Essas ações baseadas em preceitos morais estão associadas: 1) à evolução negativa do cuidado e intervenção terapêutica; 2) ao aumento do sentimento de desamparo; 3) a novas tentativas, muitas ainda mais graves; 4) ao desencorajamento de novas buscas de ajuda, de forma a esboçar um caminho oposto ao ideal de eficácia terapêutica; etc (11-12). 
A marginalização envolvendo os pacientes que tentaram suicídio acarreta, em geral, abordagens inadequadas, precarização do cuidado e violação dos direitos dos mesmos. Essa realidade não se expressa apenas pela mediação do estigma - alicerçado historicamente pelo tripé pecado, crime e loucura -, mas também pelo despreparo das equipes e de ações do poder público para lidar com o fenômeno (11), que contam com escassas estratégias de capacitação dos profissionais ou de promoção de políticas e programas de prevenção. Esse cenário denuncia a precariedade da política instituída e a fragilidade da prática dos serviços no que tange à proteção da vida e ao resguardo das condições de saúde física e mental do paciente em risco de suicídio.

\section{Violações de direitos humanos dos pacientes em risco de suicídio no Brasil}

O Observatório de Bioética e Direitos Humanos dos Pacientes do Programa de PósGraduação em Bioética da Universidade de Brasília (UnB), por meio da pesquisa qualitativa realizada no processo de elaboração do seu Relatório sobre Direitos Humanos dos Pacientes em Risco de Suicídio no Brasil - que consistiu na realização de entrevistas semiestruturadas com profissionais de saúde, pacientes e familiares de quatro capitais brasileiras, Salvador, Brasília, Goiânia e Porto Alegre, durante os meses de julho e agosto de 2017 -, identificou uma série de violações aos direitos humanos dos pacientes em risco de suicídio (7). São reflexões apontadas no Relatório:

Constata-se, nos serviços de saúde, a ausência de abordagem preventiva de novas tentativas de suicídio tão logo esses pacientes são admitidos em um serviço de emergência, bem como a não presença de profissionais de saúde que saibam identificar e notificar uma tentativa de suicídio e encaminhar os pacientes para serviços especializados de atenção psicossocial. Da mesma forma, não se provê informação adequada ao paciente acerca de aspectos do seu diagnóstico, tratamento e possibilidades de acolhimento na rede de saúde.

O paciente em risco/tentativa de suicídio é, muitas vezes, preterido na fila do atendimento em função de discriminação, bem como a provisão do cuidado em saúde, em inúmeras situações, é restrito às sequelas físicas da tentativa (traumas, perfurações, hemorragias, intoxicações), negligenciando os aspectos psicossociais que motivaram ou condicionaram a tentativa. 
Há prescrições médicas, infundadas e/ou sem análise criteriosa, de quartos de isolamento; restrição forçada ao leito; monitoração constante; restrição de acesso à alimentação e higiene; e restrição de acesso à analgesia.

O desrespeito à autonomia do paciente é recorrente, uma vez que a tentativa de suicídio é muito frequentemente atribuída a um transtorno mental e/ou a um estado passageiro ou permanente de descontrole.

Verifica-se a violação da privacidade e da confidencialidade das informações pessoais, por meio de práticas que expõem partes do corpo de pessoas inconscientes após a tentativa e o debate coletivo acerca de dados dos prontuários de determinado paciente, a despeito do seu não consentimento. Ademais, é pratica ordinária a divulgação a familiares da situação do suicídio e da condição de saúde do paciente pelo profissional de saúde sem autorização prévia. Nesse sentido, há ainda casos em que a divulgação da informação sobre o paciente é especulação manifesta, curiosidade e/ou falatório entre as pessoas da equipe de saúde.

Comumente, tem-se o emprego de tratamento hostil e humilhante para com os pacientes, que podem ser legitimados por meio de um discurso pedagógico, religioso ou moral a fim de que "aprendam" com a experiência negativa e não tentem outra vez. São frequentes os usos de expressões como: "você não queria morrer, agora aguenta a dor!"; "da próxima, vez pula do décimo andar. Pular do quarto não mata."; "você cortou seus pulsos errado, dá próxima deve cortar assim"; "toma a caixa toda de remédios e morre logo para não dar trabalho"; "você não quer morrer, quer chamar a atenção"; "da próxima vez faz direito" (7).

A relação do profissional de saúde e paciente, no caso do suicídio, há que ser considerada sob a ótica da vulnerabilidade do paciente e da necessidade de impulsionar sua autonomia e autovalor, por isso é importante que o profissional seja consciente, atento e cuidadoso em relação aos direitos humanos dos pacientes e ao respeito às suas características pessoais, como culturais, religiosas, bem como aos seus valores e crenças. A condenação moral do suicídio, exteriorizada por meio do uso de medidas de punição no atendimento e a hipervalorizarão do entendimento da vida como dever, cria uma ambiência propícia para a discriminação do paciente em risco/tentativa de suicídio (7).

Embora se presuma que os profissionais de saúde busquem o bem do paciente, há contundentes relatos nacionais e internacionais de práticas perpetradas por profissionais 
de saúde que degradam e desumanizam os pacientes - agravadas quando se trata de pacientes com transtornos mentais e/ou em risco de suicídio. Tais violações, calcadas na discriminação do paciente, interferem negativamente nos cuidados em saúde, aumentando o sofrimento do paciente e o risco de nova tentativa, o que conduz à percepção de que há um entendimento silencioso e uma autorização implícita, nas instituições de saúde, para a perpetração desses atos (7).

Da mesma forma, há um desconhecimento geral acerca da temática dos direitos humanos dos pacientes, seja por profissionais, seja por pacientes e familiares. Assim, fazse necessária a adoção de uma postura ativa de promoção da cultura de respeito a esses direitos, de mitigação do preconceito e da não estigmatização do paciente em risco/tentativa de suicídio. Recomenda-se um investimento mais amplo na elaboração de políticas públicas intersetoriais sobre o tema do suicídio, sob a perspectiva dos direitos humanos, inclusive uma Política Nacional para Prevenção do Suicídio que ainda não existe no Brasil, com destinação de recursos para os serviços da rede de saúde e para a educação permanente dos profissionais. Essa política, aliada à adoção de medidas legislativas que indiquem expressamente os direitos humanos dos pacientes, balizando a conduta dos profissionais, constituirão o resultado do esforço normativo essencial para a abordagem do tema no Brasil (7).

No mesmo sentido, revela-se necessária uma frente de fortalecimento do debate e da circulação de informações sobre o suicídio e os direitos humanos dos pacientes, com a inserção desses temas em cursos de graduação, aperfeiçoamento e especialização para profissionais de saúde, além de campanhas responsáveis no âmbito da mídia, de modo a sensibilizar a sociedade e desestimular a estigmatização e a discriminação dos pacientes (7).

\section{Considerações finais}

De forma inédita, o Observatório de Bioética e Direitos Humanos abordou a temática dos direitos humanos dos pacientes em risco/tentativa de suicídio, pesquisando sobre as violações de tais direitos no Brasil envolvendo profissionais de saúde, familiares e pacientes. Com base no referencial teórico-normativo adotado e no Relatório produzido pelo Observatório, entendemos que, no Brasil, não houve a incorporação da linguagem dos direitos humanos no âmbito dos cuidados em saúde, em geral, e, particularmente, no que 
tange ao suicídio. Desse modo, o reconhecimento de que os pacientes em risco/tentativa de suicídio são titulares de direitos humanos no momento em que são cuidados ainda não é uma realidade. De maneira oposta, o estigma e a moralidade se apresentaram como orientadores das condutas dos profissionais de saúde; foram detectadas inúmeras situações de violações, cujas ocorrências deflagram despreparo das equipes, e, consequentemente, desencorajamento de nova busca de ajuda por parte dos pacientes, aumento do sentimento de desamparo dos mesmos, potencialização do risco de suicídio e novas tentativas. Há que se adotar medidas para promover a alteração de tal quadro, dentre essas, enfatiza-se a imperiosidade de se aprovar legislação sobre direitos dos pacientes e uma Política Nacional de Prevenção ao Suicídio, bem como inserir na formação dos profissionais de saúde capacitação temática e conteúdo de direitos humanos, em consonância com os padrões internacionais.

\section{Referências}

1. World Health Organization. 2014. Preventing Suicide. A global imperative. Disponível em: http://www.who.int/mental_health/suicide-prevention/world_report_2014/en/ [Acesso em 6 out. 2018].

2. Ministério da Saúde. Portaria $n^{\circ} 1.876$, de 14 de agosto de 2006. Disponível em: http://pfdc.pgr.mpf.mp.br/atuacao-e-conteudos-de-apoio/legislacao/saudemental/portarias/portaria-ms-1876-2006j [Acesso em 6 out. 2018].

3. Neury JNB et al. Comportamento suicida na comunidade: fatores associados à ideação suicida". Revista Brasileira de Psiquiatria 27, n¹, 2005.

4. Semiotti EP, Paranhos ME, Thiers VO. Intervenção em crise e suicídio, análise de artigos indexados. Disponível em: http://www.psicologia.com.pt/artigos/textos/A0297.pdf [Acesso em 6 out. 2018].

5. Marquetti F. O suicídio como espetáculo da metrópole: cenas, cenários e espectadores. São Paulo: Faap-Unifesp, 2011.

6. Vidal CEL, Gontijo ED. Tentativas de suicídio e o acolhimento nos serviços de urgência: a percepção de quem tenta. Cad. Saúde Colet. 21, nº 2, 2013.

7. Observatório de Bioética e os Pacientes. Relatório sobre Direitos Humanos dos Pacientes em Risco de Suicídio. Disponível em: https://www.observatoriopaciente.com.br/ 2017/09/19/relatorio-sobre-direitos-humanos-dos-pacientes-em-risco-de-suicidio-no-brasil/ [Acesso em 6 out. 2018].

8. Albuquerque A. Direitos Humanos dos Pacientes. Curitiba: Juruá, 2016. 
9. Cohen J, Ezer T. Human rights in patient care: a theoretical and practical framework. Health and Human Rights Journal 15, $\mathrm{n}^{\circ}$ 2, 2013.

10. Mol A. The logic of care: health and the problem of patient choice. Oxon: Routledge, 2008.

11. Silva TPS, Sougey EB, Silva J. Estigma social no comportamento suicida: reflexões bioéticas. Rev. Bioética, 23, $n^{\circ} 2,2015$.

12. Tavares M. Suicídio e os desafios para a psicologia. Disponível em: https://site.cfp.org. br/wp-content/uploads/2013/12/Suicidio-FINAL-revisao61.pdf [Acesso em 6 out. 2018].

13. Carvalho-Rigo S. A morte pode esperar? Clínica Psicanalítica do Suicídio. Salvador: Associação Científica Campo Psicanalítico, 2014.

14. Organização Mundial de Saúde. Prevenção do Suicido: um manual para profissionais da saúde em atenção primária. Disponível em: https://www.who.int/mental_health/ prevention/suicide/en/suicideprev_phc_port.pdf [Acesso em 6 out. 2018]. 